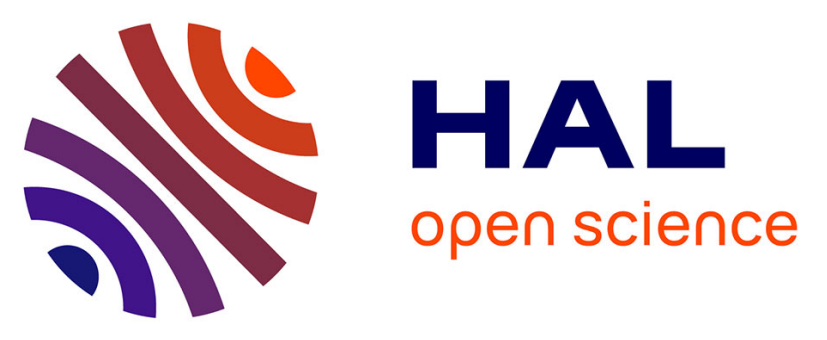

\title{
Morphological and Structural Evolution of Co3O4 Nanoparticles Revealed by in Situ Electrochemical Transmission Electron Microscopy during Electrocatalytic Water Oxidation
}

\author{
Nathaly Ortiz Peña, Dris Ihiawakrim, Madeleine Han, Benedikt \\ Lassalle-Kaiser, Sophie Carenco, Clément Sanchez, Christel Laberty-Robert, \\ David Portehault, Ovidiu Ersen
}

\section{- To cite this version:}

Nathaly Ortiz Peña, Dris Ihiawakrim, Madeleine Han, Benedikt Lassalle-Kaiser, Sophie Carenco, et al.. Morphological and Structural Evolution of Co3O4 Nanoparticles Revealed by in Situ Electrochemical Transmission Electron Microscopy during Electrocatalytic Water Oxidation. ACS Nano, 2019, 13 (10), pp.11372-11381. 10.1021/acsnano.9b04745 . hal-02342909

\section{HAL Id: hal-02342909 \\ https: / hal.sorbonne-universite.fr/hal-02342909}

Submitted on 10 Nov 2020

HAL is a multi-disciplinary open access archive for the deposit and dissemination of scientific research documents, whether they are published or not. The documents may come from teaching and research institutions in France or abroad, or from public or private research centers.
L'archive ouverte pluridisciplinaire HAL, est destinée au dépôt et à la diffusion de documents scientifiques de niveau recherche, publiés ou non, émanant des établissements d'enseignement et de recherche français ou étrangers, des laboratoires publics ou privés. 


\title{
Morphological and Structural Evolution of $\mathrm{Co}_{3} \mathrm{O}_{4}$
}

\author{
Nanoparticles Revealed by In Situ Electrochemical
}

\section{Transmission Electron Microscopy during}

\section{Electrocatalytic Water Oxidation}

Nathaly Ortiz Peña ${ }^{1}$, Dris Ihiawakrim ${ }^{1}$, Madeleine Han ${ }^{2,3}$, Benedikt Lassalle-Kaiser, ${ }^{3}$ Sophie Carenco $^{2}$, Clément Sanchez ${ }^{2}$, Christel Laberty-Robert ${ }^{2}$, David Portehault ${ }^{2}$, Ovidiu Ersen ${ }^{1 *}$

${ }^{1}$ Institut de Physique et Chimie des Matériaux de Strasbourg (IPCMS), UMR 7504 CNRS Université de Strasbourg, 23 rue du Loess, BP 43, Strasbourg Cedex 2, France

${ }^{2}$ Sorbonne Université, CNRS, Collège de France, Laboratoire Chimie de la Matière Condensée de Paris, 4 Place de Jussieu, 75005 Paris, France

${ }^{3}$ Synchrotron SOLEIL, L'Orme des Merisiers, Saint-Aubin, 91192 Gif sur Yvette, France

* Corresponding authors:

ovidiu.ersen@ipcms.unistra.fr

david.portehault@sorbonne-universite.fr 


\section{ABSTRACT}

Unveiling the mechanism of electrocatalytic processes is fundamental for the search of more efficient and stable electrode materials for clean energy conversion devices. Although several in situ techniques are now available to track structural changes during electrocatalysis, especially of water oxidation, a direct observation, in real space, of morphological changes of nanostructured electrocatalysts is missing. Herein, we implement an in situ electrochemical Transmission Electron Microscopy (in situ EC-TEM) methodology for studying electrocatalysts of the oxygen evolution reaction (OER) during operation, by using model cobalt oxide $\mathrm{Co}_{3} \mathrm{O}_{4}$ nanoparticles. The observation conditions were optimized to mimic standard electrochemistry experiments in a regular electrochemical cell, allowing to perform cyclic voltammetry and chronopotentiometry in similar conditions in situ and ex situ. This in situ EC-TEM method enables us to observe the chemical, morphological and structural evolutions occurring in the initial nanoparticle-based electrode exposed to different aqueous electrolytes and under OER conditions. The results show that surface amorphization occurs, yielding a nanometric cobalt (oxyhydr)oxide-like phase during OER. This process is irreversible and occurs to an extent that has not been described before. Furthermore, we show that the $\mathrm{pH}$ and counter-ions of the electrolytes impact this restructuration, shedding light on the materials properties in neutral phosphate electrolytes. In addition to the structural changes followed in situ during the electrochemical measurements, this study demonstrates that it is possible to rely on in situ electrochemical TEM to reveal processes in electrocatalysts while preserving a good correlation with ex situ regular electrochemistry.

\section{KEYWORDS}

in situ electrochemical transmission electron microscopy, electrocatalysis, cobalt oxide, oxygen evolution reaction, morphological transformation. 
The efficiency of emergent clean energy technologies, such as metal-air batteries, water electrolyzers or fuel cells, is intimately linked to the optimization of the electrode materials performing the oxygen evolution reaction (OER). ${ }^{1}$ Indeed, overcoming the stagnant kinetics of OER is a paramount goal that drives the development of electrocatalysts.

Transition metal oxides based on earth-abundant elements are attracting major attention in the field, since some of them present high activity towards the OER ${ }^{1}$ at lower costs than precious metals. They also offer a wide spectrum of compositions to tune their catalytic properties. $^{2}$ Despite great fundamental and technological interest of metal oxide electrocatalysts, their evolution in OER conditions remains elusive. Understanding structural and morphological changes would enable paving the way for the improvement of their performances in terms of activity, selectivity and stability. ${ }^{3}$ In OER conditions, bonds are formed and broken at the surface of the electrocatalyst. ${ }^{4}$ As a consequence, chemical and structural changes are likely to occur at the nanometer or sub-nanometer scale. To address these transformations, in situ observations are mandatory. Such studies are focusing increasing efforts, which rely mostly, ${ }^{5}$ but not exhaustively, on X-ray absorption (XAS), ${ }^{6} \mathrm{X}$-ray emission, ${ }^{7} \mathrm{X}$-ray photoelectron, ${ }^{8}$ and Raman $^{9}$ spectroscopies. These techniques are useful to detect structural and electronic changes during OER, but do not provide any information on morphological changes.

In situ electrochemical transmission electron microscopy (EC-TEM) uses dedicated sample holders enabling to perform electrochemical studies in a liquid electrolyte under an electron beam. This methodology is among the most recent ones that have been implemented in TEM and also as in situ techniques for studying electrochemical processes. ${ }^{5}$ In situ EC-TEM is widely used to study the structural evolution of Li-ion batteries electrodes during cycling. ${ }^{10-12}$ In these devices, Li (de)insertion occurs in the whole volume of the particles making the related structural and morphological changes relatively easy to track. In contrast, electrocatalytic events often occur at the surface of the materials, where a small geometrical area, possibly a 
few nanometer-thick layer, is involved during the process, thus pushing further the requirements in terms of sensitivity and spatial resolution, among others. The scarce works on in situ ECTEM for electrocatalysis have focused on electrocatalysts made of relatively stable precious metals, ${ }^{13-15}$ especially for the oxygen reduction reaction (ORR), where particles etching has been evidenced. Materials with a more complex structure and free of precious metals are sought for $^{1,2}$ but may show deeper transformations under electrocatalytic conditions. Hence, more intricate evolution processes are still to be discovered. Besides, while several works have addressed ORR electrocatalysts ${ }^{16,17}$, there is no report on in situ EC-TEM for OER electrocatalysts.

The spinel $\mathrm{Co}_{3} \mathrm{O}_{4}$ is a case study of low-cost and efficient electrocatalyst towards the OER in alkaline media, where structural evolution involves multiple phenomena beyond simple etching of the surface. Several authors have pointed out that the actual active species are $\mathrm{Co}^{4+}$ cations, which appear only above the onset potential and get reduced upon return to non-catalytic conditions. ${ }^{18-22}$ Despite the various examples of OER electrocatalysts based on $\mathrm{Co}_{3} \mathrm{O}_{4}$ nanoparticles, there is no insight on the evolution of the morphology of the particles and on the reversibility of these structural and morphological transformations. One of the clearest attempts to solve this question was done by Bergmann et al. ${ }^{23}$ who used a combination of XAS performed on quenched electrodes, and in situ grazing-incident X-ray diffraction (GIXRD). In their work, the appearance of the active $\mathrm{Co}^{4+}$ species was related to a reversible formation of an amorphous sub-nanometer shell of $\mathrm{CoO}_{\mathrm{x}}(\mathrm{OH})_{\mathrm{y}}$ on $\mathrm{Co}_{3} \mathrm{O}_{4}$. Although this approach provided the first insights into the changes that $\mathrm{Co}_{3} \mathrm{O}_{4}$ nanoparticles experience during OER, no information on the morphological evolutions could be retrieved. Hence, $\mathrm{Co}_{3} \mathrm{O}_{4}$ nanoparticles appear as an ideal candidate for in situ EC-TEM in OER conditions. Such an analytical approach should complete the knowledge acquired with previous spectroscopic studies ${ }^{23}$ by 
providing a direct view, in real time and real space, of both morphological and structural changes during OER.

Herein we first describe the in situ EC-TEM set-up in relation with a classical three-electrodes cell, pointing out the challenges in implementing the methodology and the suggested set of solutions including sample deposition, observation modes, and in situ vs. ex situ electrochemistry conditions. We then apply in situ electrochemical TEM to water oxidation over $\mathrm{Co}_{3} \mathrm{O}_{4}$ nanoparticles in alkaline and neutral electrolytes under various electrochemical conditions. We finally highlight and discuss the nanocatalysts morphological and structural modifications taking place during OER.

\section{RESULTS AND DISCUSSION}

\section{Morphological evolution monitored by in situ STEM during cyclic voltammetry}

The in situ electrochemical TEM holder is depicted in Figure 1A. It consists in a disposable miniaturized 3-electrodes cell, called hereafter electrochemical chip, on its tip. The chip (Figure 1B, C) possesses a working electrode made of glassy carbon (GC) placed over an electron-transparent silicon nitride window. Two Pt electrodes act as pseudo-reference and counter electrodes (Figure 1C), respectively. The deposited particles can be observed during electrochemical experiments through a liquid electrolyte about $500 \mathrm{~nm}$ thick. $^{24}$ 


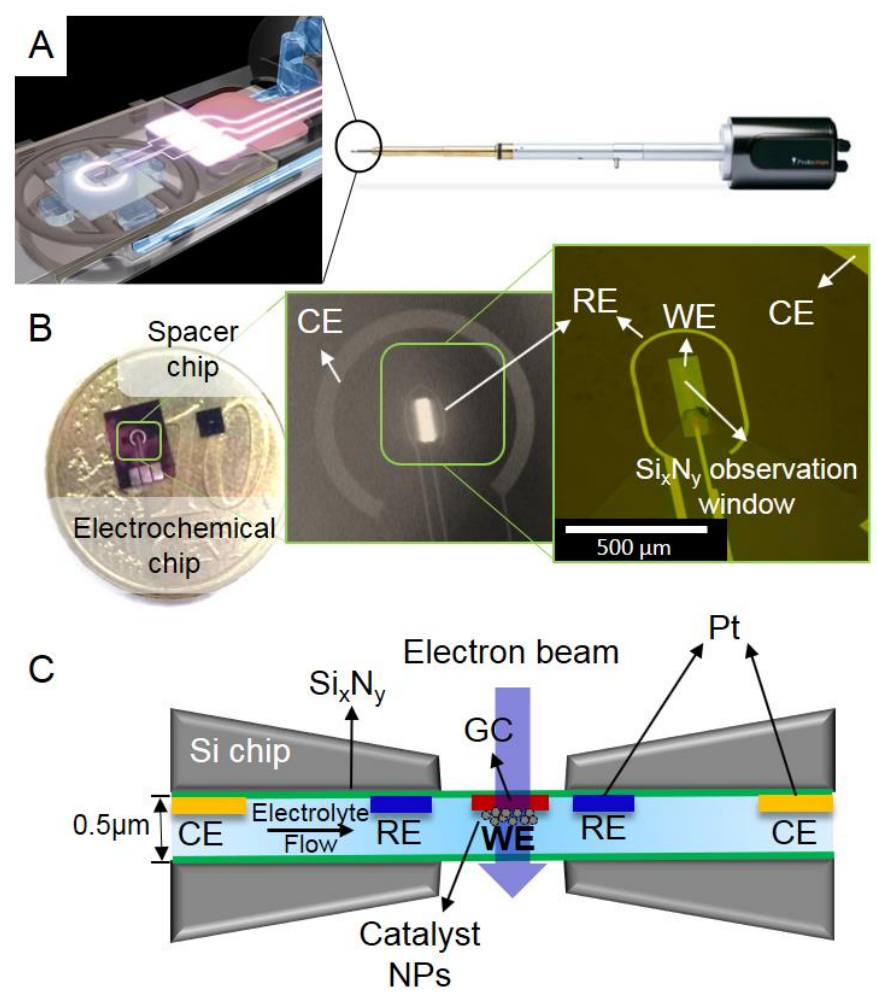

Figure 1. (A) In situ liquid electrochemical Poseidon $(\mathbb{C}$ TEM holder from Protochips $($ (the inset shows the tip of the holder where the miniaturized electrochemical cell is integrated. Taken from ref. ${ }^{25}$ ). (B) In situ disposable chip positioned at the tip of the sample holder and zoom-in on the working and reference electrode central area of the chip. The working electrode is made of glassy carbon and the reference electrode is actually a pseudo-reference of Pt. The counter electrode is also made of Pt. (C) Transversal schematic view of the assembled cell. WE, $\mathrm{CE}$ and RE are the working, counter and pseudo-reference electrodes, respectively. GC is the glassy carbon current collector in the WE. The radial distances between WE and RE and between RE and CE are $\sim 90 \mu \mathrm{m}$ and $\sim 500 \mu \mathrm{m}$, respectively.

For clarity, throughout the manuscript, "in situ" TEM analyses refer to the samples observed in the e-chips in contact with the electrolyte and during electrochemical measurements. "Post in situ" TEM analyses refer to the samples observed in the e-chips after the end of the electrochemical measurements and the removal of the electrolyte, "Ex situ post mortem" TEM 
analyses refer to the samples observed on a common carbon-coated carbon grid after retrieval of the material from a glassy carbon rotating disk electrode after electrochemical operation of the material in a classical lab-scale three electrodes set-up.

First, we observed the $\mathrm{Co}_{3} \mathrm{O}_{4}$ nanoparticles (Figure 2A) drop-casted on the observation window of the chip, without any liquid. The nanoparticles with diameter between 10 and $15 \mathrm{~nm}$ formed $100 \mathrm{~nm}$-scale agglomerates over the glassy carbon electrode. Thereafter, the $0.1 \mathrm{M}$ $\mathrm{KOH}$ electrolyte solution was continuously flowed in the chip (Figure 2B). By using the TEM observation mode, corresponding to a parallel electron beam and large electron dose, the electrochemical measurements were strongly affected by the electron beam irradiation, according to the voltammograms (Figure S1 in supporting information). Hence, the scanning (S)TEM mode was chosen, minimizing the effect of the beam on the electrochemical behavior upon cyclic voltammetry (Figure S2). STEM also provides better spatial resolution and especially images with a better signal to noise ratio (SNR), by enabling precise focus on the particles deposited over the working electrode, placed in the top window of the cell (Figure 2A) $\cdot{ }^{26,27}$ The conditions of electron illumination were optimized in STEM mode in order to set the appropriate conditions for minimizing the beam effect on the particles and electrochemical measurements (Figure S3). No modification of the morphology and of the structure of the nanoparticles was observed after they were put in contact with the flow of electrolyte (Figure 2B and Figure S4). 

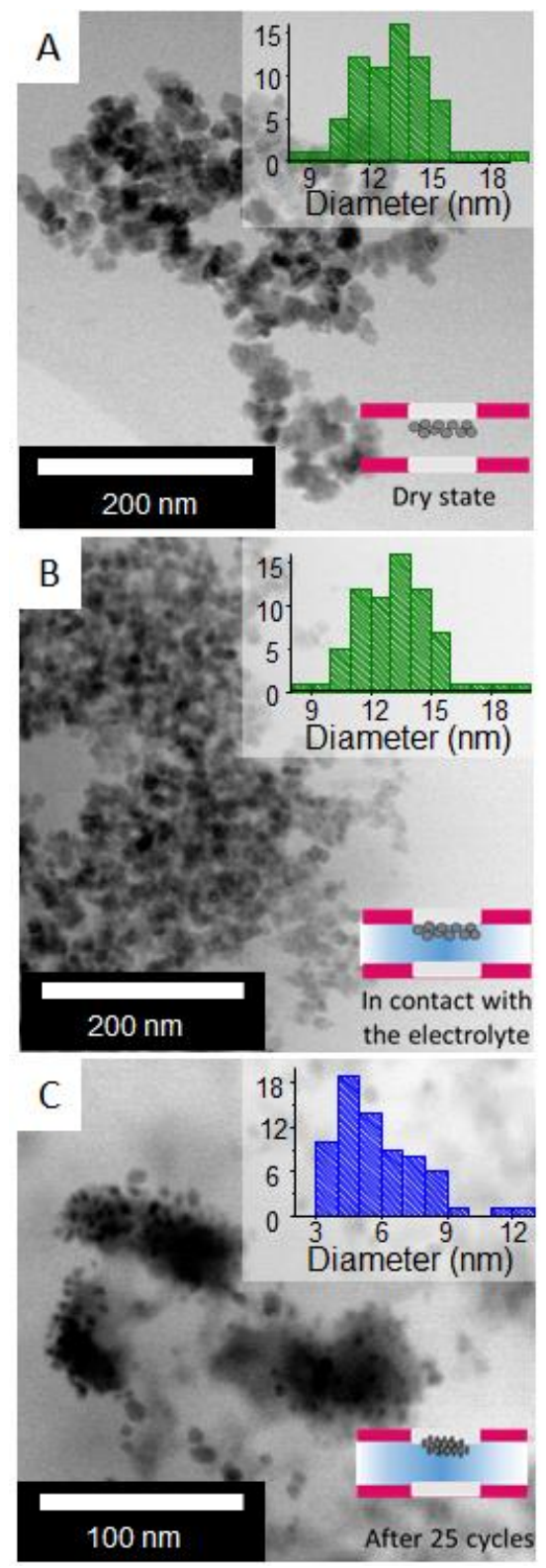

Figure 2. In situ STEM images of $\mathrm{Co}_{3} \mathrm{O}_{4}$ nanoparticles deposited over the glassy carbon electrode in the observation window of the electrochemical TEM sample holder: particles (A) as-prepared in the dry state, (B) in contact with a $0.1 \mathrm{M} \mathrm{KOH}$ electrolyte before electrochemical measurements, (C) after 25 voltammetric cycles from $0.6 \mathrm{~V}$ to $1.8 \mathrm{~V} v \mathrm{~s}$. RHE in a $0.1 \mathrm{M} \mathrm{KOH}$ aqueous electrolyte at $20 \mathrm{mV} \mathrm{s}^{-1}$. Top insets in $\mathrm{A}, \mathrm{B}$ and $\mathrm{C}$ show the corresponding size distributions. Lower insets schematize the in situ EC-TEM cell and the location of the sample on the cell window. 


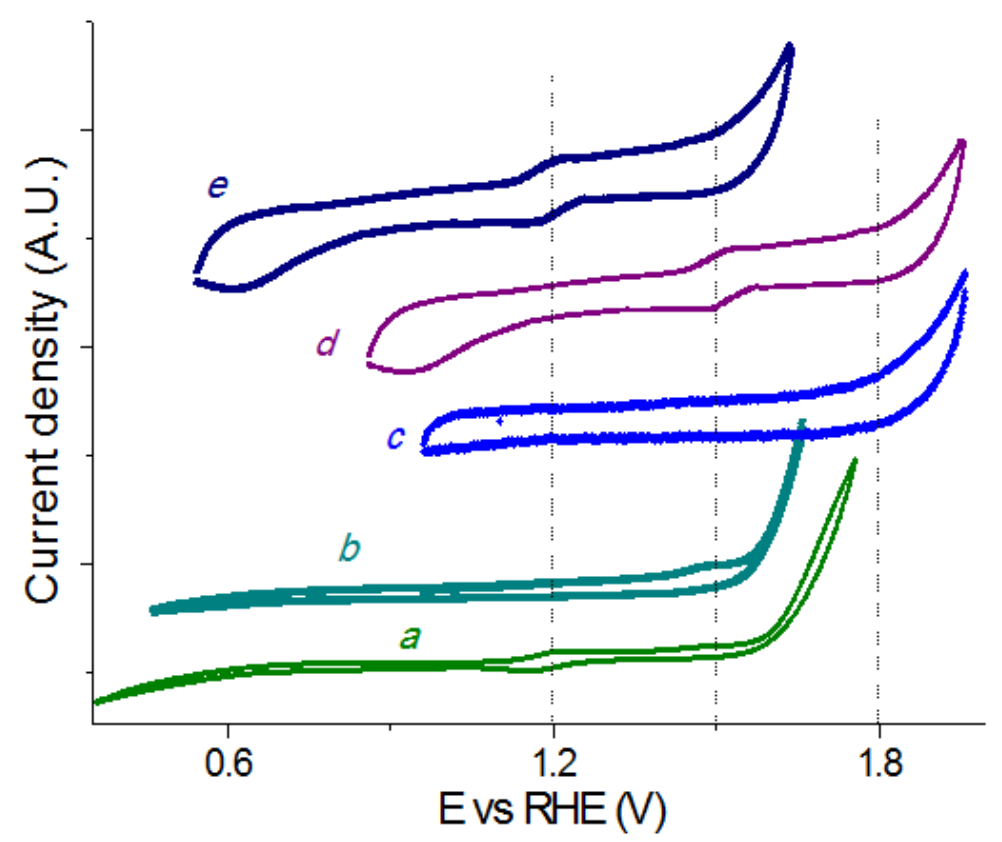

Figure 3. Voltammetry cycles (2nd cycle) recorded at $100 \mathrm{mV} \mathrm{s}^{-1}$ ex situ and in situ by using electrodes of $\mathrm{Co}_{3} \mathrm{O}_{4}$ nanoparticles with (a) and without (b) the $\mathrm{Fe}(\mathrm{CN})_{6}{ }^{3-} / \mathrm{Fe}(\mathrm{CN})_{6}{ }^{4-}$-couple as internal reference in a $0.1 \mathrm{M} \mathrm{KOH}$ aqueous electrolyte, in a classical three-electrodes electrochemical cell with a Pt pseudo-reference electrode ("ex situ" curves), and in the in situ electrochemical TEM holder, without (c) and with (d) the internal reference, respectively. The curve (d) "in situ internal reference corrected" corresponds to the curve (d) "in situ internal reference" which was shifted in order to align the redox wave of the reference couple with the one measured ex situ.

In order to ensure that the electrochemical potential window within the miniaturized cell corresponds to the same range into a typical ex situ three-electrodes set-up, the reference redox couple $\mathrm{Fe}(\mathrm{CN})_{6}{ }^{3-} / \mathrm{Fe}(\mathrm{CN})_{6}{ }^{4-}(1.2 \mathrm{~V}$ vs. RHE) was introduced in the electrolyte as internal reference, curve (a). The potential was recalibrated using the $\mathrm{Fe}(\mathrm{CN})_{6}{ }^{3-} / \mathrm{Fe}(\mathrm{CN})_{6}{ }^{4-}$ redox potential with respect to an $\mathrm{Ag} / \mathrm{AgCl}$ reference electrode and a Pt wire ( Figure S5). The cyclic voltammograms $(\mathrm{CV})$ recorded at $100 \mathrm{mV} \mathrm{s}^{-1}$ (Figure 3) show that the redox waves of the reference couple in situ and ex situ are shifted by $0.3 \mathrm{~V}$. After realignment of the potential scales 
by taking into account this shift, the CV curves are very close. They span a potential range between $0.6 \mathrm{~V}$ and $1.8 \mathrm{~V} / \mathrm{RHE}$ and exhibit similar shapes. After correction of the in situ potential scale, the most important difference between ex situ and in situ recorded CV curves is the higher polarization in the in situ cell, which may account for the impossibility to polish the electrode in the in situ set-up and the heterogeneous dispersion of the nanoparticles in the surface of the working electrode.

The same electrode area described above (Figure 2A and 2B) was observed in situ during cyclic voltammetry (Figure 2C) within the liquid. After 25 cycles at $20 \mathrm{mV} \mathrm{s}^{-1}$, the diameter of the $\mathrm{Co}_{3} \mathrm{O}_{4}$ nanoparticles decreased to around $5 \mathrm{~nm}$ (Figure 2C). The lighter contrast around the nanoparticles after cycling indicates the presence of a low electron density matrix embedding the particles. A similar observation was obtained after $125 \mathrm{CV}$ cycles at $100 \mathrm{mV} \mathrm{s}^{-1}$ (Figure 4E, see Figure S6 for typical in situ voltammograms) for $9 \mathrm{~nm}$ nanoparticles. It showed particle size decrease and growth of a low contrast matrix (Figure 4F). Chemical mapping by Energy Dispersive X-Ray spectroscopy-coupled STEM (STEM-EDX) was performed on the electrode material before cycling and after the 125 cycles at $100 \mathrm{mV} \mathrm{s}^{-1}$ (Post in situ). It indicated that the particles as well as the surrounding matrix are made of both cobalt and oxygen (Figures $4 \mathrm{C}$ D and 4G-H). 

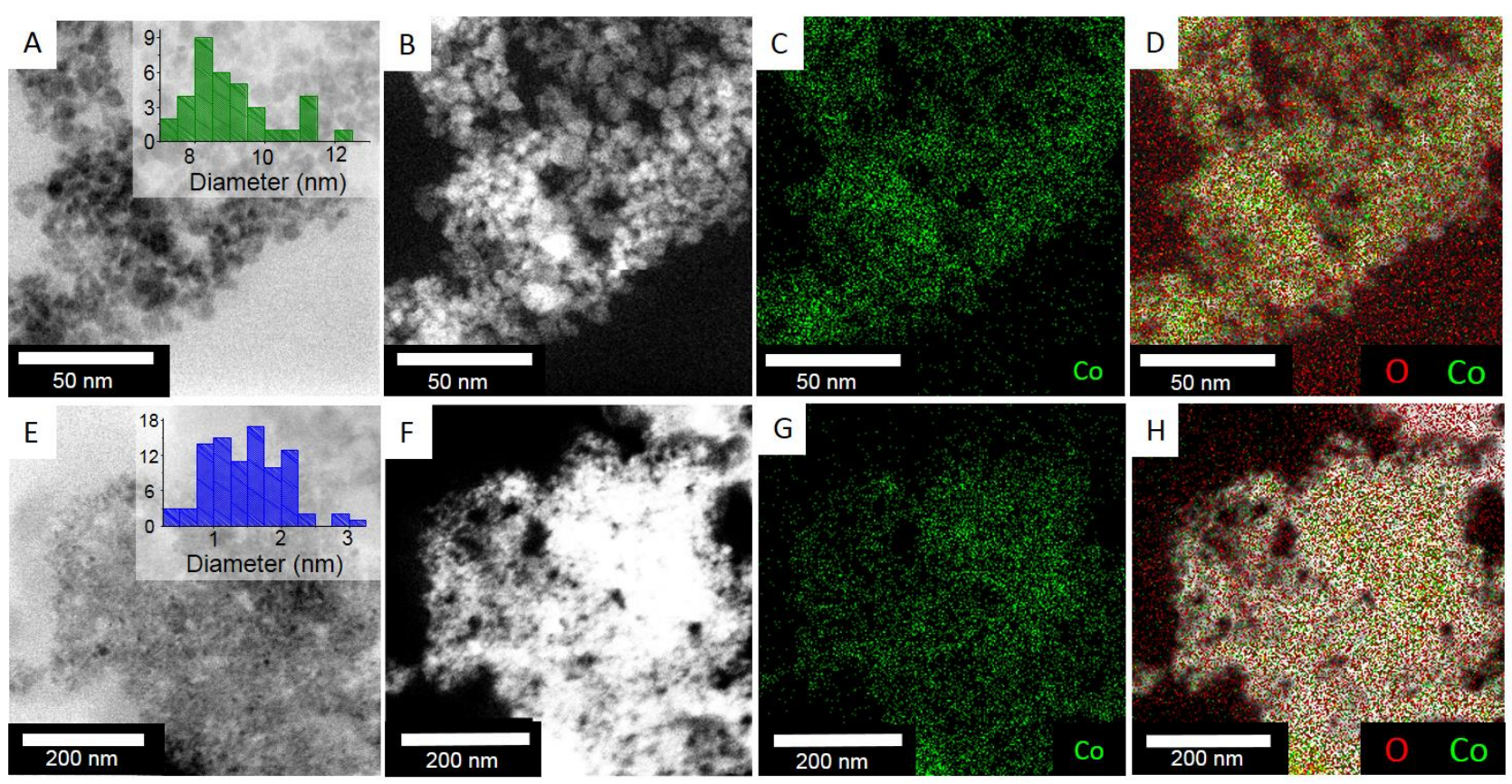

Figure 4. Analytical study of $\mathrm{Co}_{3} \mathrm{O}_{4}$ nanoparticles deposited on the electrode of the in situ electrochemical TEM holder (A-D) in the dry state, (E-H) after 125 cycles (post in situ) from $0.6 \mathrm{~V} / \mathrm{RHE}$ to $1.8 \mathrm{~V} / \mathrm{RHE}$ in a $0.1 \mathrm{M} \mathrm{KOH}$ aqueous electrolyte at $100 \mathrm{mV} \mathrm{s}^{-1}$. Bright field STEM images (A) before and (E) after cycling. STEM images recorded in High Angular Annular Dark Field (HAADF) mode of the same regions (B) before and (F) after cycling. (C, G) Corresponding elemental maps of Co $(\mathrm{K} \alpha)$. (D, H) Corresponding composite maps of Co (green) and O (red) superimposed to the STEM-HAADF images. Insets in (A) and (E) show the size distributions of the nanoparticles before and after cycling.

Overall, direct observation by in situ electrochemical STEM of the formation of the matrix and of the particle diameter decrease suggests a structural modification of the outer part of the initial nanoparticles into a less dense cobalt oxide arrangement. No hint of atom-scale ordering within this matrix could be retrieved by high-resolution TEM (HRTEM, post in situ) after cycling thus suggesting an amorphous character. The observed composition and atom-scale disorder of the matrix are in agreement with previous reports suggesting the formation of an amorphous cobalt (oxyhydr)oxide-like phase during OER with $\mathrm{Co}_{3} \mathrm{O}_{4}$ materials. ${ }^{23,28}$ Such a 
restructuration occurs when the material is repeatedly exposed to potentials high enough to trigger OER, in agreement with the conclusions of Bergmann et al. ${ }^{23}$ who proposed a surface amorphization of $\mathrm{Co}_{3} \mathrm{O}_{4}$ nanoparticles above the OER onset potential in a neutral phosphate buffer $\left(\mathrm{KP}_{\mathrm{i}}\right)$ aqueous electrolyte. However, a significant difference arises between the previous observations made from in situ grazing-incident X-ray diffraction (GIXRD) and from quenched- X-ray absorption edge spectroscopy $(\mathrm{XAS})^{23}$ on one side, and our in situ TEM results on the other side. While the formers report amorphization at high potential that is fully reversible when the electrode goes back at its resting state, we observed the irreversible growth of an amorphous layer upon voltammetric cycling, leading to the formation of an amorphous matrix embedding the remaining crystalline fractions. To probe the extent of such irreversible amorphization in basic $\mathrm{KOH}$ aqueous electrolyte, we have submitted a $\mathrm{Co}_{3} \mathrm{O}_{4}$ nanoparticlesbased electrode to more severe OER conditions, by using chronopotentiometry in the OER conditions in aqueous $0.1 \mathrm{M} \mathrm{KOH}$ electrolyte in the in situ electrochemical TEM holder.

\section{Morphological evolution monitored by in situ STEM during chronopotentiometry}

The morphological evolution of $\mathrm{Co}_{3} \mathrm{O}_{4}$ nanoparticles was monitored while applying a $10 \mathrm{~mA} \mathrm{~cm} \mathrm{GC}^{-2}$ current density during $10 \mathrm{~min}$ (Figure 5). The chronopotentiometry curve is similar to those previously reported in the literature, ${ }^{29,30}$ with a steep increase of the potential over the first $30 \mathrm{~s}$, then a slower increase. Cyclic voltammograms recorded before and after chronopotentiometry did not show significant changes of the electrochemical response of the material (Figure S7). Over a period of around 120 s, STEM images show the growth of a matrix embedding smaller crystalline nanoparticle (Supporting movie M1). As mentioned above, this matrix is assigned to an amorphous cobalt (oxyhydr)oxide-like phase. The overall area of the chosen agglomerate increased by $8 \%$ up to $120 \mathrm{~s}$ and then became steady. The persistence of bright areas in the STEM-HAADF images shows that dense nano-domains were maintained 
and that the amorphization process of the particles into a lesser density solid is not complete. The in situ STEM chronopotentiometry experiment (Figure 5) is consistent with the in situ STEM CV study (Figure 2C and Figure 4), showing extended amorphization of the spinel nanoparticles in the course of OER. The resulting amorphous cobalt (oxyhydr)oxide-like phase is then exposed to the electrolyte and is probably at the origin of the electrocatalytic activity, ${ }^{31}$ with the formation of $\mathrm{Co}^{4+}$ species according to the literature. ${ }^{18,31,32}$
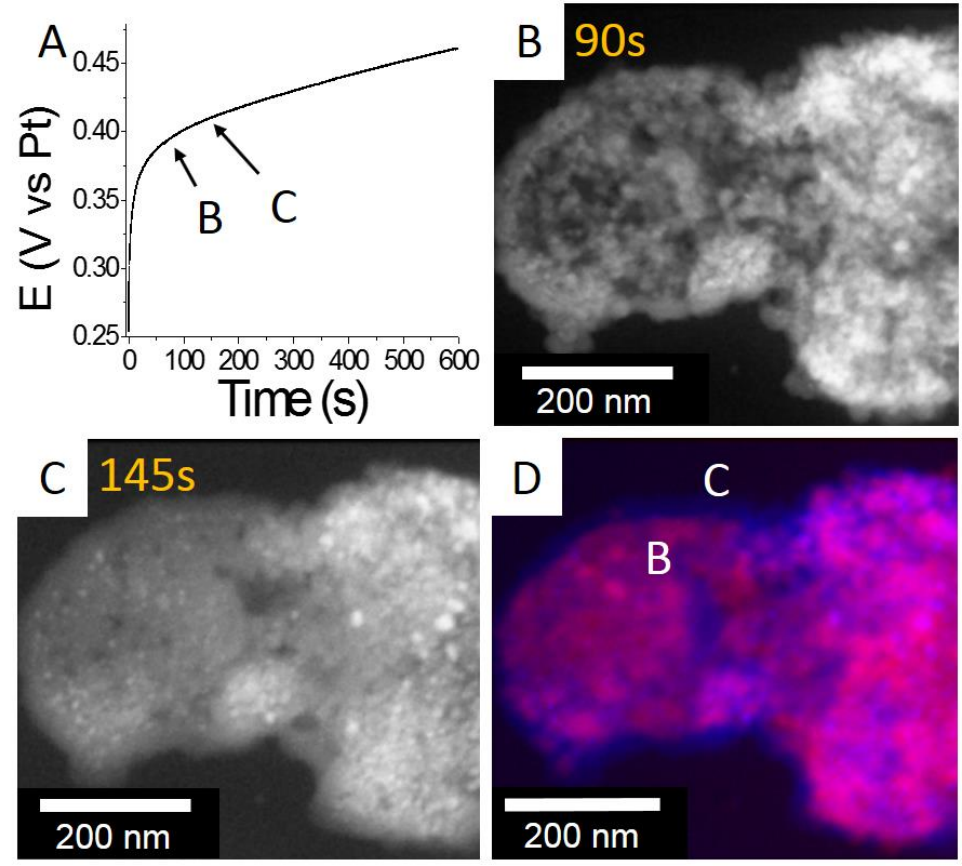

Figure 5. (A) In situ electrochemical TEM chronopotentiometry experiment at $10 \mathrm{~mA} \mathrm{~cm}_{\mathrm{GC}}{ }^{-2}$ in aqueous $0.1 \mathrm{M} \mathrm{KOH}$ electrolyte for $10 \mathrm{~min}$ : time evolution of the electrode potential vs. $\mathrm{Pt}$ and of the area of a nanoparticles agglomerate. STEM-HAADF images recorded at 90s (B) and $145 \mathrm{~s}$ (C). (D) Superposition of B and C evidencing the evolution of the area of the agglomerate at time 90 in red and 145 in blue.

The fact that amorphous/crystalline components are also present in regions away from the illuminated area further indicates that the amorphization is not caused by the electron beam. To confirm this statement and rule out any synergistic effect between electrochemistry and the extended exposition to the electron beam, chronopotentiometry and CV experiments were 
performed ex situ in the same conditions as in situ. Both electrode materials were observed post mortem by STEM (Figure 6B and 6C, Figure S8). Similar amorphous/crystalline composite containing smaller particles embedded into a less dense matrix were observed both in situ and ex situ. The electrodes were further analyzed to get deeper understanding of the nature of this matrix and of the remaining nanoparticles.
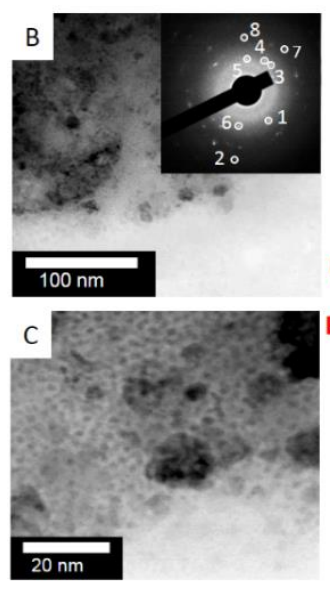

mixture of $\mathrm{CoO}, \mathrm{CoOOH}$ and $\mathrm{Co}(\mathrm{OH})_{2}$

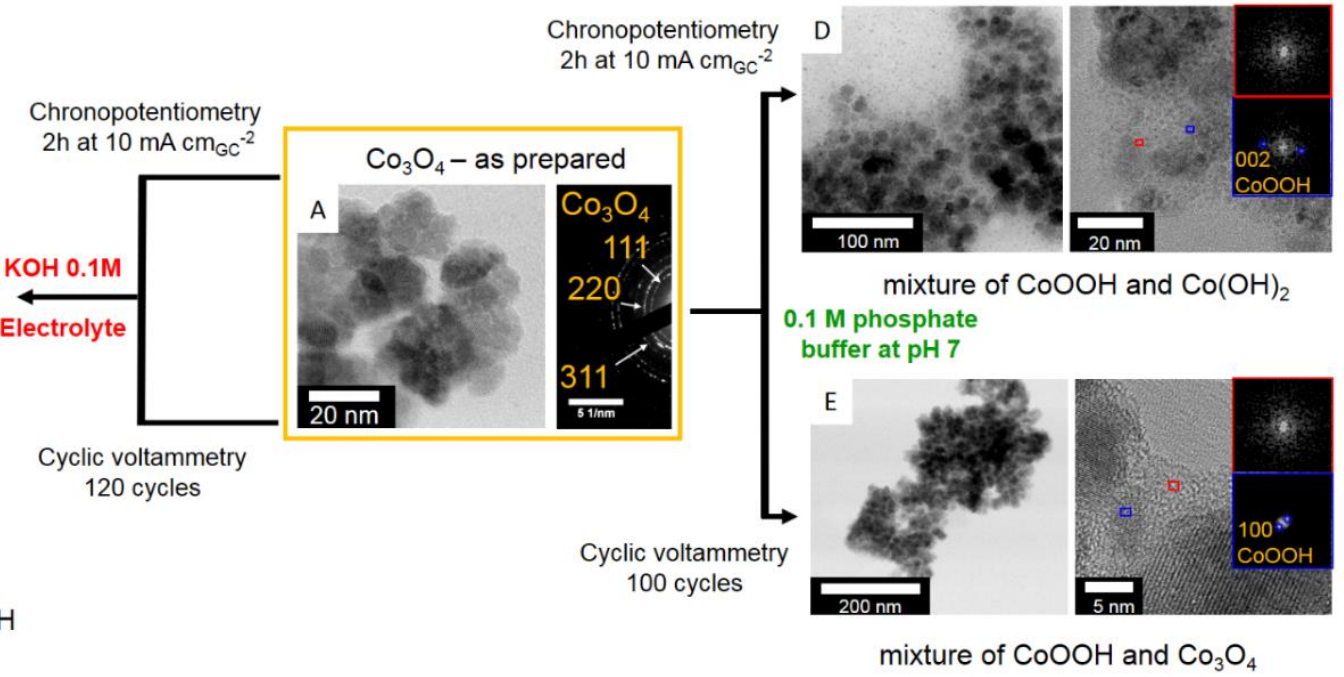

Figure 6. Bright field STEM images and diffraction patterns of (A) as prepared $\mathrm{Co}_{3} \mathrm{O}_{4}$, (B) $\mathrm{Co}_{3} \mathrm{O}_{4}$ after $2 \mathrm{~h}$ of chronopotentiometry at $10 \mathrm{~mA} \mathrm{~cm}^{-2}$ in aqueous $0.1 \mathrm{M} \mathrm{KOH}$ electrolyte (inset: diffraction pattern displaying a mixture of $\mathrm{CoOOH}\left(1-[100] ; 2-[200]\right.$; 3-[100]), $\mathrm{Co}(\mathrm{OH})_{2}$ (4-[101]; 5-[100]) and $\mathrm{CoO}(6-[111] ; 7,8-[220]))$. (C) $\mathrm{Co}_{3} \mathrm{O}_{4}$ after $120 \mathrm{CV}$ cycles from 0.6 to $1.8 \mathrm{~V}$ vs. RHE in aqueous $0.1 \mathrm{M} \mathrm{KOH}$ electrolyte. (D) $\mathrm{Co}_{3} \mathrm{O}_{4}$ after $100 \mathrm{CV}$ from 0.6 to $1.8 \mathrm{~V}$ vs. RHE in KPi as electrolyte. (E) $\mathrm{Co}_{3} \mathrm{O}_{4}$ after $2 \mathrm{~h}$ of chronopotentiometry at $10 \mathrm{~mA} \mathrm{~cm}^{-2}$ in neutral KPi aqueous electrolyte. The data from the $\mathrm{KOH}$ electrolyte were acquired in post in situ conditions (ex situ post mortem conditions yield identical data). For KPi, the data were acquired in ex situ post mortem conditions. 


\section{Structural evolution: post mortem study}

Selected area electron diffraction (SAED, Figure 6B) performed on the electrode material recovered after chronopotentiometry in aqueous $0.1 \mathrm{M} \mathrm{KOH}$ electrolyte for $2 \mathrm{~h}$, using the in situ set-up as well as the classical three electrode cell (post in situ and ex situ post mortem conditions), shows that the $\mathrm{Co}_{3} \mathrm{O}_{4}$ structure has disappeared. In both cases, the diffraction patterns display concomitant phases assigned to a mixture of $\mathrm{CoO}, \mathrm{CoOOH}$ and $\mathrm{Co}(\mathrm{OH})_{2}$ phases, thus indicating that the initial $\mathrm{Co}_{3} \mathrm{O}_{4}$ particles have transformed after prolonged OER into other cobalt-oxo phases and an amorphous (oxyhydr)oxide-like matrix. Electron energy loss spectroscopy (EELS) performed on the electrode in the miniaturized EC-TEM cell before and after chronopotentiometry confirms this observation (Figure 7), with a significant change in the cobalt $\mathrm{L}_{3} / \mathrm{L}_{2}$ intensity ratio from the initial electrode to the post mortem electrode. The as prepared $\mathrm{Co}_{3} \mathrm{O}_{4}$ nanoparticles displayed an $\mathrm{L}_{3} / \mathrm{L}_{2}$ ratio of $c a .2 .8$ in agreement with the mixed valence $\mathrm{Co}^{\mathrm{II}} / \mathrm{Co}^{\mathrm{III}}$ expected in $\mathrm{Co}_{3} \mathrm{O}_{4}{ }^{33}$ After chronopotentiometry, a $\mathrm{L}_{3} / \mathrm{L}_{2}$ ratio of $c a .4 .8$ was observed, suggesting $\mathrm{Co}^{2+}$ species as the major component. This result confirms the assignment of the remaining nanoparticles to $\mathrm{CoO}, \mathrm{CoOOH}$ and $\mathrm{Co}(\mathrm{OH})_{2}$, and strongly supports the presence of $\mathrm{Co}^{2+}$ species also in the amorphous phase after electrochemical experiments. Hence, the electrode analyzed post mortem comprises $\mathrm{CoO}, \mathrm{CoOOH}$ and $\mathrm{Co}(\mathrm{OH})_{2}$ nanoparticles embedded into an amorphous $\mathrm{CoO}_{\mathrm{x}} \mathrm{H}_{\mathrm{y}}$ matrix containing $\mathrm{Co}^{2+}$ species. Overall, consistent observations between in situ and ex situ studies show that in aqueous $0.1 \mathrm{M} \mathrm{KOH}$ electrolyte, $\mathrm{Co}_{3} \mathrm{O}_{4}$ nanoparticles decompose irreversibly into smaller $\mathrm{Co}^{2+}$-based $\left(\mathrm{CoO}\right.$ and $\left.\mathrm{Co}(\mathrm{OH})_{2}\right)$ and $\mathrm{Co}^{3+}$-based $(\mathrm{CoOOH})$ nanoparticles within an extended amorphous cobalt (oxy)hydroxide matrix. The latter contains $\mathrm{Co}^{2+}$ when isolated post mortem, but is most probably oxidized into $\mathrm{Co}^{3+} / \mathrm{Co}^{4+}$ species in the OER conditions, according to previous results. ${ }^{18-22}$ This would also agree with a recent report that has accounted for a similar behavior in alkaline OER conditions of the spinel $\mathrm{NiCo}_{2} \mathrm{O}_{4},{ }^{34}$ for which in situ Raman measurements showed that the initial spinel 
irreversibly transforms into a poorly ordered (oxyhydr)oxide-like phase and rock salt $\mathrm{CoO}$ in alkaline OER conditions. Further in situ investigations will be necessary to assess in situ the electronic state of Co during OER, especially by in situ XAS to avoid the limitations of EELS, which can only be performed in the dried cell.

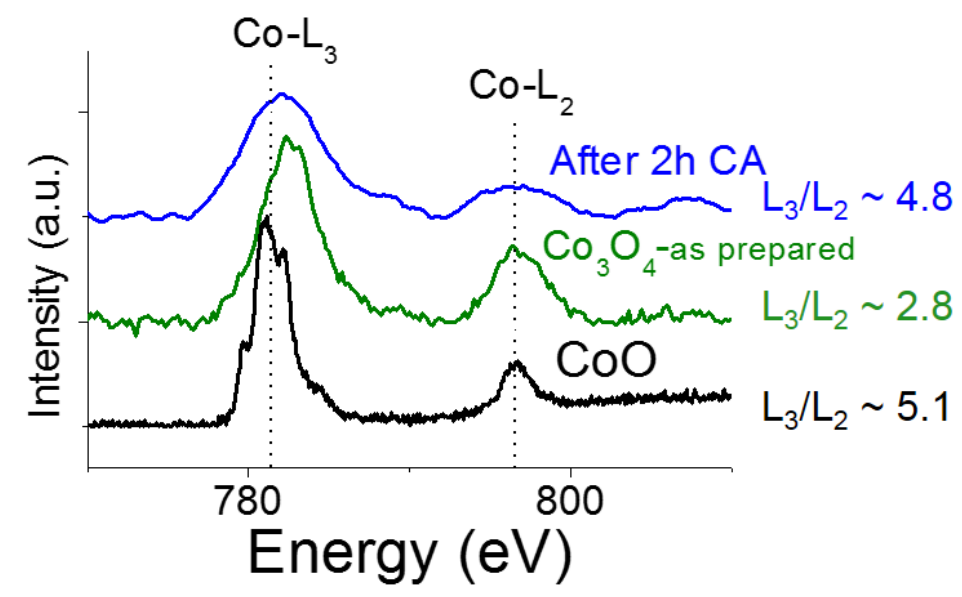

Figure 7. Co K edge EEL spectra of $\mathrm{CoO}$ (black), as prepared $\mathrm{Co}_{3} \mathrm{O}_{4}$ (green) and catalyst after $2 \mathrm{~h}$ of chronopotentiometry measurements (blue) at $10 \mathrm{~mA} \mathrm{~cm} \mathrm{GC}^{-2}$ in aqueous $0.1 \mathrm{M} \mathrm{KOH}$ (post in situ). $\mathrm{CoO}$ spectra was taken from the EELS database. ${ }^{35}$

Although we have obtained consistent evidences of extended and irreversible amorphization of the $\mathrm{Co}_{3} \mathrm{O}_{4}$ nanoparticles surface, this observation appears in contradiction with other reports mentioning reversible structural modifications of $\mathrm{Co}_{3} \mathrm{O}_{4}$ materials. ${ }^{23,28}$ The reversibility of this transformation may be impacted by the crystallographic facets exposed by the material. ${ }^{36}$ This could explain the discrepancy between our observation of irreversible amorphization of nanoparticles and the reversible surface amorphization of an oriented $\mathrm{Co}_{3} \mathrm{O}_{4}(111)$ thin film. ${ }^{28}$

Another factor possibly influencing surface amorphization is the nature of the aqueous electrolyte, including $\mathrm{pH}$ and counter ions. Previous in situ measurements of reversible amorphization of $\mathrm{Co}_{3} \mathrm{O}_{4}$ nanoparticles have been performed in a neutral phosphate buffer (KPi) electrolyte. ${ }^{23}$ In order to assess the influence of the electrolyte, we have studied by STEM and 
EDX the electrode after ex situ cyclic voltammetry (Figures S9, S10, S13 and Figure 6E) and chronopotentiometry (Figure S11 and Figure 6D) in the KPi electrolyte. As in alkaline medium, the particles average diameter decreased during OER, down to 1-2 nm under chronopotentiometry conditions after $2 \mathrm{~h}$. Lattice planes typical of the interlayer distance (002) of $\mathrm{CoOOH}$ were observed in some $\sim 2 \mathrm{~nm}$ nanoparticles. Other sheet-like nanostructures were detected, typical of lamellar phases like $\mathrm{CoOOH}$ and $\mathrm{Co}(\mathrm{OH})_{2}$ (Figure S12). Some areas from the surrounding phase showed no evidence of structuration, thus suggesting that the matrix is again amorphous, as in basic medium. Chemical mapping did not evidence the presence of phosphorus (Figure S13). Thus, the matrix is an amorphous cobalt (oxyhydr)oxide-like phase, as in the alkaline $\mathrm{KOH}$ electrolyte. When using the same KPi electrolyte but under cyclic voltammetry (Figure 6E), morphological changes are less apparent, with no significant change in the particle size. Some 1-2 nm crystalline domains were nevertheless observed with dspacing typical of $\mathrm{CoOOH}$. They are embedded by a $3 \mathrm{~nm}$-thick amorphous layer. These TEM observations complete the structural information reported by Bergmann et al. ${ }^{23}$ under cyclic voltammetry. Indeed, although $\mathrm{Co}_{3} \mathrm{O}_{4}$ appears in TEM as the main phase, thus confirming that structural changes are limited, we observe the formation of a thin amorphous layer in an irreversible manner that was not detected by structural studies, ${ }^{23}$ which appear not sensitive enough to surface states. Chronopotentiometry under OER conditions implies larger charge transfer per experimental time unit than cyclic voltammetry ones. These more stringent conditions yield extended and irreversible amorphization, as it was the case in the alkaline electrolyte. In a phosphate-free $\mathrm{KCl}$ electrolyte with the same $\mathrm{pH}$ as the $\mathrm{KPi}$ electrolyte, more important structural and morphological changes were observed after $2 \mathrm{~h}$ of chronopotentiometry (Figure S14), including extended crystallization of $\mathrm{Co}(\mathrm{OH})_{2}, \mathrm{CoOOH}$ and $\mathrm{Co}_{3} \mathrm{O}_{4}$, with no evidence of potassium insertion in the final material (Figure S15). As in the case of $\mathrm{KOH}$ and $\mathrm{KPi}$ electrolytes, evolutions are less marked in $\mathrm{CV}$ conditions. At the same $\mathrm{pH}$ the phosphate 
buffer provides higher OER activity than the $\mathrm{KCl}$ electrolyte (Figure S9). In addition, the amorphous matrix grown around the initial $\mathrm{Co}_{3} \mathrm{O}_{4}$ particles appears mandatory to trigger high OER activity. This corroborates the hypothesis that this amorphous cobalt (oxyhydr)oxide-like phase is the actual electrocatalytic material in the material studied herein, initially made of sole $\mathrm{Co}_{3} \mathrm{O}_{4}$ nanoparticles. The difference in reactivity in $\mathrm{KPi}$ and $\mathrm{KCl}$ at the same $\mathrm{pH}$ is not ascribed to the presence of phosphates in the material obtained in $\mathrm{KPi}$, as phosphorus could not be detected by EDS in the electrode material. This suggests that the amorphous cobalt (oxyhydr)oxide-like phase forming during OER at the surface of $\mathrm{Co}_{3} \mathrm{O}_{4}$ nanoparticles is not subjected to the self-healing mechanism that Nocera et al. evidenced on electrodeposited electrocatalyst Co-Pi, an amorphous cobalt (oxyhydr)oxide-like phase containing where phosphates were incorporated. ${ }^{37-39}$ On the contrary, phosphates into the KPi electrolyte can act as proton acceptors to fasten $\mathrm{OER}$ compared to the $\mathrm{KCl}$ electrolyte. ${ }^{40}$ Likewise, $\mathrm{Cl}^{-}$ions can trigger larger morphological changes by nucleophilic catalysis of oxide restructuration. ${ }^{41}$ Furthermore, morphological and structural changes are less marked in KPi with neutral conditions than in basic $\mathrm{KOH}$ electrolyte, where cobalt-oxo species are however less soluble. ${ }^{41,42}$ Therefore, extensive restructuration in aqueous $\mathrm{KOH}$ is not related to dissolutionreprecipitation of the Co-based material, but can be traced back to the OER process, in agreement with previous reports that ascribe formation of a layered cobalt oxyhydroxide-like phase to the transition of initial $\mathrm{Co}^{2+}{ }_{\mathrm{Td}}$ species in $\mathrm{Co}_{3} \mathrm{O}_{4}$ to $\mathrm{Co}^{3+}$ Oh species into the layered phase. ${ }^{23,43}$ The cyclic voltammograms recorded in the different electrolytes show that at a given potential $v s$. RHE, higher current and hence higher OER rate are reached in $\mathrm{KOH}$ than in $\mathrm{KPi}$, which exemplifies the more favorable kinetics of OER in the basic electrolyte. The faster OER would in turn trigger faster structural evolution and amorphization in $\mathrm{KOH}$ than in the phosphate buffer, thus suggesting that the OER rate and the amorphization rate are related, presumably through the amount of transferred charges. 
Overall, under operation of the $\mathrm{Co}_{3} \mathrm{O}_{4}$-based electrodes, surface amorphization occurs (Figure 8) to an extent that depends on the nature of the electrolyte and on the electrochemical conditions. In some of the most common conditions (alkaline electrolyte and/or chronopotentiometry), the amorphous phase becomes the major component of the electrode. Its formation is not reversible but it is also responsible for the water oxidation activity.

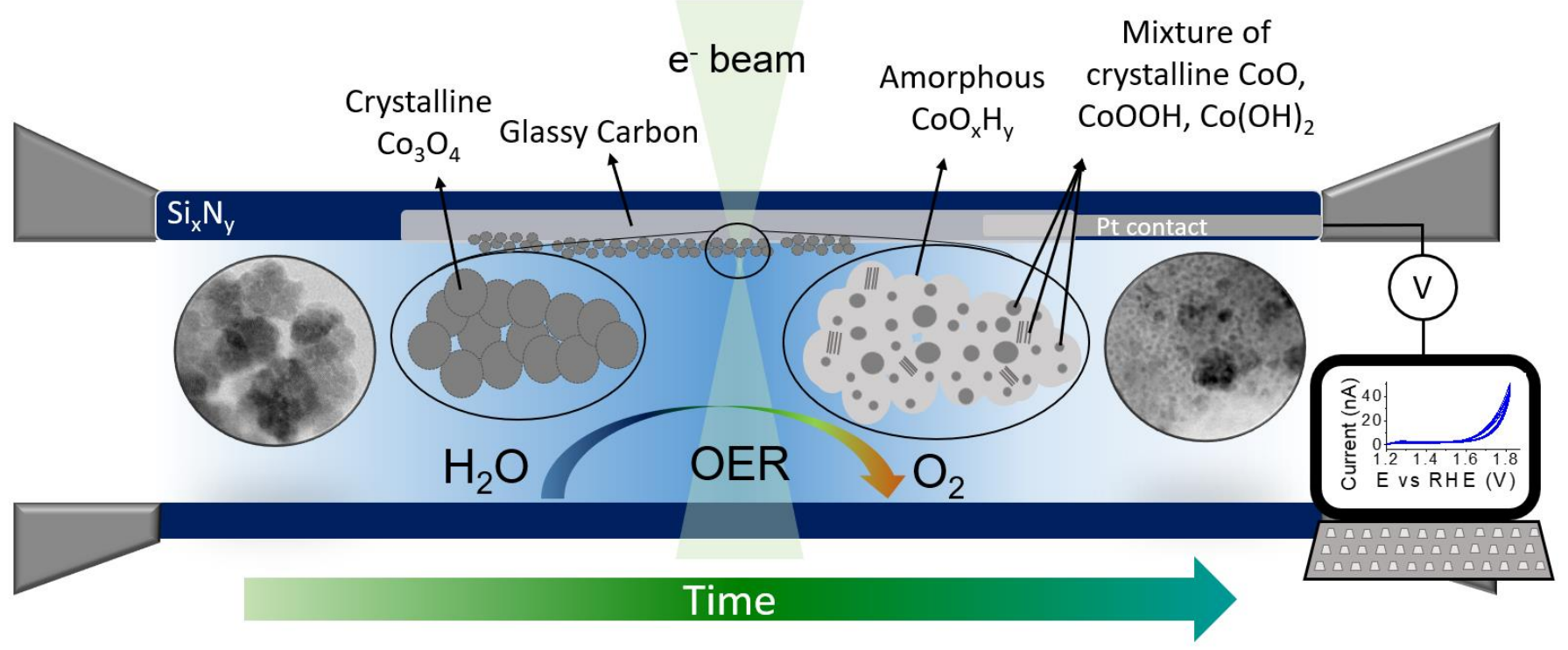

Figure 8. Scheme of the evolution of $\mathrm{Co}_{3} \mathrm{O}_{4}$ nanoparticles during oxygen evolution, as revealed by in situ electrochemical STEM.

\section{CONCLUSIONS}

In summary, we have assessed the structural and morphological transformations of cobalt oxide spinel nanoparticles in operation conditions for the oxygen evolution reaction. The study was performed by in situ electrochemical transmission electron microscopy after thorough evaluation of the role of the observation conditions, including electron dose, electrochemical conditions and electrolyte's nature. Optimized conditions allow direct tracking of the catalyst nanostructure in relation with the electrochemical measurements within the electrolyte. In addition to the imaging modes, the in situ cell can also be conveniently used for other complementary structural and chemical analyses, including selected area diffraction, energy 
dispersive and electron energy loss spectroscopies performed post mortem, on the used electrodes after removal of the electrolyte. Electrodes studied electrochemically in situ as well as ex situ can then be analyzed by STEM, yielding a more complete picture of the composition, microstructure and phase transformations induced by the electrocatalytic process.

Therefore, we could directly observe the gradual amorphization of $\mathrm{Co}_{3} \mathrm{O}_{4}$ nanoparticles during water oxidation process. Such amorphization reaches a plateau after a couple of minutes in the observation conditions, whatever the electrolyte used (basic $\mathrm{KOH}$ or neutral phosphate buffer). This restructuration appears beneficial to the water oxidation electrocatalytic activity and demonstrates that the amorphous phase formed in the course of the reaction is the active species for electrocatalytic $\mathrm{OER}$ on $\mathrm{Co}_{3} \mathrm{O}_{4}$ nanoparticle-based materials, as previously mentioned by other groups. ${ }^{23}$ However, contrary to some previous reports, our observations unambiguously show that the material amorphization is not reversible in the electrochemical conditions studied, especially under constant current, which corresponds to the most operational conditions of water splitting electrochemical cells.

According to these conclusions, in situ electrochemical TEM provides specific advantages to assess electrocatalysts:

(i) In situ observation ensure that the compositional, structural and morphological analyzes are performed on nanoparticles actually involved in the electrochemical reactions, while post mortem analyzes cannot warrant that the materials analyzed were indeed involved in the reaction. In this work, we have especially ensured that the nanoparticles studied were in contact with the electrode and involved in electrocatalytic processes.

(ii) Likewise, in situ electrochemical TEM can be used to validate or improve a protocol for less time demanding post mortem analyzes, once the data obtained by both 
approaches have been shown to be consistent. In this direction, we have used in situ studies to ensure that structural and morphological evolutions were occurring because of the electrocatalytic process, and not because of exposure to the electrolyte or because of post mortem drying of the electrode material, for instance.

(iii) Like many other in situ techniques, in situ electrochemical TEM can be used to detect steady states not stable after drying for post mortem observation, or elusive states difficult to quench. This track will be followed in the near future for non-model electrocatalysts.

All in all, the work reported herein sets the basic experimental parameters in order to use in situ electrochemical TEM for highlighting structural changes in electrocatalytic materials, using conditions as close as possible to those encountered in regular lab bench set-ups, and closer to more advanced electrocatalysis devices.

\section{MATERIALS AND METHODS}

All chemicals were purchased from Sigma-Aldrich and used as received, except Acetylene Black, purchased from Alfa Aesar.

\section{Catalyst nanoparticles synthesis}

The $\mathrm{Co}_{3} \mathrm{O}_{4}$ nanoparticles were produced through a microwave-assisted hydrothermal synthesis by modifying a protocol reported recently. ${ }^{44} \mathrm{Co}\left(\mathrm{NO}_{3}\right)_{2} \cdot 6 \mathrm{H}_{2} \mathrm{O}$ was solubilized in $35 \mathrm{~mL}$ of deionized water at a concentration of $0.02 \mathrm{~mol} \mathrm{~L}^{-1}$. The $\mathrm{pH}$ was then adjusted to 11.5 by addition of an ammonia solution at $28 \mathrm{wt} . \%$. The reaction medium was aged by stirring under air for $1 \mathrm{~h}$. The suspension was then divided into 2 aliquots of ca. $20 \mathrm{~mL}$. Each of these aliquots was heated into a monomode microwave oven (Anton Paar Monowave 300) with a 10 s heating ramp at $800 \mathrm{~W}$ followed by a $10 \mathrm{~min}$ dwell time. Each aliquot was then washed by 5 
cycles of centrifugation-redispersion into milliQ water. The recovered powders were dried overnight under vacuum at $40{ }^{\circ} \mathrm{C}$.

\section{Catalyst ink preparation}

Two types of ink composition were tested ex situ. The first one contained $10 \mathrm{mg}$ of $\mathrm{Co}_{3} \mathrm{O}_{4}$, Acetylene Black (AB, Alfa Aesar) $\left(99.9+\%, 75 \mathrm{~m}^{2} \mathrm{~g}^{-1}\right)$ and $10 \mathrm{~mL}$ of absolute ethanol. This mixture was sonicated during $2 \mathrm{~h}$. Then, the dispersion was cooled down to room temperature and $435 \mu \mathrm{L}$ of ion-exchanged Nafion $\subset$ solution (5 wt. \% in aliphatic alcohols, Aldrich) was added immediately. The mixture was then sonicated again until a stable dispersion was reached.

This is a classical composition to test electrocatalytic OER properties. ${ }^{45}$ A second ink was tested, comprising only $10 \mathrm{mg}$ of $\mathrm{Co}_{3} \mathrm{O}_{4}$ and $10 \mathrm{~mL}$ of absolute ethanol, without any additives. For the in situ EC-TEM experiments, only the second carbon-free ink was used to avoid decomposition of Nafion(C) under the beam and to avoid the dilution of $\mathrm{Co}_{3} \mathrm{O}_{4}$ nanoparticles by AB particles.

\section{Electrode preparation and electrochemistry}

Ex situ electrochemistry. An electrochemical workstation VPS Biologic potentiostat equipped with a rotating disk working electrode $(1600 \mathrm{rpm})$ was used to evaluate ex situ the OER properties of a thin-layer film of $\mathrm{Co}_{3} \mathrm{O}_{4}$ nanoparticles. The working electrode consisted of a $3 \mathrm{~mm}$ diameter glassy carbon (GC) disk covered by a thin-layer film of electrocatalyst obtained by drop casting of the inks described above. The counter electrode was a Pt wire. An $\mathrm{Ag} / \mathrm{AgCl} /$ saturated $\mathrm{KCl}$ electrode was used as reference. Prior to the deposition of the ink, the GC electrodes $\left(0.07 \mathrm{~cm}^{2}\right.$, Radiometer Analytical $)$ were sequentially polished using diamond paste $(1 \mu \mathrm{m}, \mathrm{BAS}$ inc.) followed by alumina paste $(0.05 \mu \mathrm{m}, \mathrm{BAS}$ inc.) to reach mirror grade. After polishing, the electrodes were sonicated in water and ethanol $10 \mathrm{~min}$ each. Then, $2 \mu \mathrm{L}$ of 
the additive-free ink (10 mg Co3O4/10 mL ethanol) were drop-casted over the GC disk and dried under static air for $1 \mathrm{~h}$. The maximum load $\left(\mathrm{Co}_{3} \mathrm{O}_{4}\right)$ over the $\mathrm{GC}$ electrode would be 28.5 $\mu \mathrm{g} \mathrm{cm}_{\mathrm{GC}^{-2}}$. A $0.1 \mathrm{M} \mathrm{KOH}$, a $0.1 \mathrm{M} \mathrm{KCl}$, and a $\mathrm{pH} 7$ phosphate buffer aqueous solutions were used as electrolytes. The buffer solution was obtained by mixing of $0.1 \mathrm{M} \mathrm{K}_{2} \mathrm{HPO}_{4}$ and $0.1 \mathrm{M}$ $\mathrm{KH}_{2} \mathrm{PO}_{4}$ aqueous solutions until $\mathrm{pH} 7$ was reached.

In situ electrochemical TEM. For the in situ liquid TEM analysis, a Protochips $($ liquid cell holder (Poseidon Select $($ 550) was used. It consists in disposable silicon chips onto which the sample is deposited. Each miniaturized cell was washed successively in HPLC-grade acetone, methanol and ethanol to remove its protective coating. Thereafter, a 2-5 $\mathrm{nm}$ carbon layer was deposited on the e-chip containing the electrodes (top chip) using a carbon evaporator. The carbon layer was introduced to reduce the drift of the nanoparticles during observation. This layer helped to better fix the nanoparticles over the observation window. Alternatively, plasma cleaning with an $\mathrm{Ar} / \mathrm{O}_{2}$ mixture during $30 \mathrm{~s}$ was also tested to improve the fixation, but the carbon layer yielded more stable samples. A drop of the $\mathrm{Co}_{3} \mathrm{O}_{4}$ ink free of $\mathrm{AB}$ and Nafion was deposited over the silicon nitride observation window through a mask to avoid the presence of the electrocatalyst in the rest of the e-chip. The mask is a microfabricated Si chip with an aperture of the same size of the observation window and the same dimensions of the e-chip to facilitate the alignment during deposition. The chip was dried under air during $1 \mathrm{~h}$ before closure of in situ cell. The maximum load over the GC electrode collector was $342 \mu \mathrm{g} \mathrm{cm}_{\mathrm{GC}^{-2}}$. From a low-magnification image, we calculate the total area of the rod-like working GC electrode (Figure 1) to be $\sim 2.810^{-5} \mathrm{~cm}^{2}$. Its thickness is $60 \mathrm{~nm}$.

. The electrolytes used were identical to those mentioned above for the ex situ studies. They were flushed into the in situ cell after its introduction into the microscope at a constant $25 \mu \mathrm{L} \mathrm{min}{ }^{-1}$ flow. During the electrochemical measurements, bubbles can be formed due to the 
oxygen evolution reaction. The dynamic processes at the surface of the nanoparticles were best observed through the formed bubbles since only a thin layer of electrolyte is preserved, thus improving the resolution. No full dewetting of the observation window could be observed. Electrochemical experiments were performed with a Gamry 600 potentiostat in a corrected JEOL $2100 \mathrm{~F} / \mathrm{Cs}(\mathrm{S}) \mathrm{TEM}$ at $200 \mathrm{kV}$, operated in continuous capture mode to yield image sequences of the dynamics during electrocatalysis. Movies were recorded at 10 frames per second in STEM mode. The electron dose was calculated as described by Woehl et al. ${ }^{46}$ High Resolution Transmission Electron Microscopy (HRTEM) images were taken before any contact with the electrolyte and after the electrochemical measurements were performed. Electron Energy Loss Spectroscopy (EELS) and Energy Dispersive Spectroscopy (EDS) analysis were performed before and after in situ and ex situ electrochemical experiments.

\section{SUPPLEMENTARY INFORMATION}

The Supporting Information is available free of charge on the ACS Publications website.

Movie S1: STEM-bright field movie recorded in situ during chronopotentiometry experiment at $10 \mathrm{~mA} \mathrm{~cm}^{-2} \mathrm{GC}$ in aqueous $0.1 \mathrm{M} \mathrm{KOH}$ electrolyte first $176 \mathrm{~s}$ accelerated at $300 \mathrm{fps}$. Figure $\mathrm{S} 1$ and S2: impact of the (S)TEM beam on the in situ electrochemical measurements. Figure S3: effect of beam current on the in situ observation in STEM. Figure S4: EELS, electron diffraction and size distribution after irradiation in the electrolyte. Figures S5, S6 and S7: additional ex situ and in situ cyclic voltammograms used to calibrate the internal reference, stability of the electrochemical response during in situ cyclic voltammetry and in situ chronopotentiometry, respectively. Figure S8: comparison between post mortem samples from the in situ set-up and from a classical rotating GC disc. Figures S9, S10 and S11: additional electrochemical measurements in KPi and $\mathrm{KCl}$ electrolytes. Figures S12, S13, S14 and S15: additional HRTEM, EDX and electron diffraction data of the post mortem samples in $\mathrm{KPi}$ and $\mathrm{KCl}$ electrolytes. 


\section{ACKNOWLEDGEMENT}

This work was supported by the French national agency for research (ANR) under the project InSiChem ANR-16-CE05-0011.

\section{REFERENCES}

(1) Roger, I.; Shipman, M. A.; Symes, M. D. Earth-Abundant Catalysts for Electrochemical and Photoelectrochemical Water Splitting. Nat. Rev. Chem. 2017, 1, 1-14.

(2) Burke, M. S.; Enman, L. J.; Batchellor, A. S.; Zou, S.; Boettcher, S. W. Oxygen Evolution Reaction Electrocatalysis on Transition Metal Oxides and (Oxy)Hydroxides: Activity Trends and Design Principles. Chem. Mater. 2015, 27, 7549-7558.

(3) Suen, N.-T.; Hung, S.-F.; Quan, Q.; Zhang, N.; Xu, Y.-J.; Chen, H. M. Electrocatalysis for the Oxygen Evolution Reaction: Recent Development and Future Perspectives. Chem. Soc. Rev. 2017, 46, 337-365.

(4) Suntivich, J.; May, K. J.; Gasteiger, H. A.; Goodenough, J. B.; Shao-Horn, Y. A Perovskite Oxide Optimized for Oxygen Evolution Catalysis from Molecular Orbital Principles. Science. 2011, 334, 1383-1385.

(5) Li, X.; Wang, H.-Y.; Yang, H.; Cai, W.; Liu, S.; Liu, B. In Situ/Operando Characterization Techniques to Probe the Electrochemical Reactions for Energy Conversion. Small Methods 2018, 2, 1700395 (1-14).

(6) Fabbri, E.; Nachtegaal, M.; Binninger, T.; Cheng, X.; Kim, B.-J.; Durst, J.; Bozza, F.; Graule, T.; Schäublin, R.; Wiles, L.; Pertoso, M.; Danilovic, N.; Ayers, K. E.; Schmidt, T. J. Dynamic Surface Self-Reconstruction Is the Key of Highly Active Perovskite NanoElectrocatalysts for Water Splitting. Nat. Mater. 2017, 16, 925-931.

(7) Gul, S.; Ng, J. W. D.; Alonso-Mori, R.; Kern, J.; Sokaras, D.; Anzenberg, E.; LassalleKaiser, B.; Gorlin, Y.; Weng, T.-C.; Zwart, P. H.; Zhang, J. Z.; Bergmann, U.; 
Yachandra, V. K.; Jaramillo, T. F.; Yano, J. Simultaneous Detection of Electronic Structure Changes from Two Elements of a Bifunctional Catalyst Using WavelengthDispersive X-Ray Emission Spectroscopy and In Situ Electrochemistry. Phys. Chem. Chem. Phys. 2015, 17, 8901-8912.

(8) Paloukis, F.; Papazisi, K. M.; Balomenou, S. P.; Tsiplakides, D.; Bournel, F.; Gallet, J. Applied Surface Science In Situ X-Ray Photoelectron Spectroscopy Study of Complex Oxides under Gas and Vacuum Environments. Appl. Surf. Sci. 2017, 423, 1176-1181.

(9) Trześniewski, B. J.; Diaz-Morales, O.; Vermaas, D. A.; Longo, A.; Bras, W.; Koper, M. T. M.; Smith, W. A. In Situ Observation of Active Oxygen Species in Fe-Containing NiBased Oxygen Evolution Catalysts: The Effect of $\mathrm{pH}$ on Electrochemical Activity. $J$. Am. Chem. Soc. 2015, 137, 15112-15121.

(10) Wheatcroft, L.; Özkaya, D.; Cookson, J.; Inkson, B. J. Towards In Situ TEM for Li-Ion Battery Research. Energy Procedia 2018, 151, 163-167.

(11) Yuan, Y.; Amine, K.; Lu, J.; Shahbazian-Yassar, R. Understanding Materials Challenges for Rechargeable Ion Batteries with In Situ Transmission Electron Microscopy. Nat. Commun. 2017, 8, 15806 (1-14).

(12) Wu, F.; Yao, N. Advances in Sealed Liquid Cells for In Situ TEM Electrochemial Investigation of Lithium-Ion Battery. Nano Energy 2015, 11, 196-210.

(13) Zhu, G.; Prabhudev, S.; Yang, J.; Gabardo, C. M.; Botton, G. A.; Soleymani, L. In Situ Liquid Cell TEM Study of Morphological Evolution and Degradation of $\mathrm{Pt}-\mathrm{Fe}$ Nanocatalysts During Potential Cycling. J. Phys. Chem. C 2014, 118, 22111-22119.

(14) Claudel, F.; Dubau, L.; Berthomé, G.; Sola-Hernandez, L.; Beauger, C.; Piccolo, L.; Maillard, F. Degradation Mechanisms of Oxygen Evolution Reaction Electrocatalysts: A Combined Identical-Location Transmission Electron Microscopy and X-Ray Photoelectron Spectroscopy Study. ACS Catal. 2019, 9, 4688-4698. 
(15) Beermann, V.; Holtz, M. E.; Padgett, E.; de Araujo, J. F.; Muller, D. A.; Strasser, P. Real-Time Imaging of Activation and Degradation of Carbon Supported Octahedral PtNi Alloy Fuel Cell Catalysts at the Nanoscale Using In Situ Electrochemical Liquid Cell STEM. Energy Environ. Sci. 2019, 12, 2476-2485.

(16) Liu, Q.; Yang, T.; Du, C.; Tang, Y.; Sun, Y.; Jia, P.; Chen, J.; Ye, H.; Shen, T.; Peng, Q.; Zhang, L.; Huang, J. In Situ Imaging the Oxygen Reduction Reactions of Solid State $\mathrm{Na}-\mathrm{O} 2$ Batteries with $\mathrm{CuO}$ Nanowires as the Air Cathode. Nano Lett. 2018, 18, 37233730.

(17) Gocyla, M.; Kuehl, S.; Shviro, M.; Heyen, H.; Selve, S.; E. Dunin-Borkowski, R.; Heggen, M.; Strasser, P. Shape Stability of Octahedral PtNi Nanocatalysts for Electrochemical Oxygen Reduction Reaction Studied by In Situ Transmission Electron Microscopy. ACS Nano 2018, 12, 5306-5311.

(18) Risch, M.; Ringleb, F.; Kohlhoff, M.; Bogdanoff, P.; Chernev, P.; Zaharieva, I.; Dau, H. Water Oxidation by Amorphous Cobalt-Based Oxides : In Situ Tracking of Redox Transitions and Mode of Catalysis. Energy Environ. Sci. 2015, 8, 661-674.

(19) Zhang, M.; de Respinis, M.; Frei, H. Time-Resolved Observations of Water Oxidation Intermediates on a Cobalt Oxide Nanoparticle Catalyst. Nat. Chem. 2014, 6, 362-367.

(20) Klingan, K.; Ringleb, F.; Zaharieva, I.; Heidkamp, J.; Chernev, P.; Gonzalez-Flores, D.; Risch, M.; Fischer, A.; Dau, H. Water Oxidation by Amorphous Cobalt-Based Oxides: Volume Activity and Proton Transfer to Electrolyte Bases. ChemSusChem 2014, 7, $1301-1310$

(21) Friebel, D.; Bajdich, M.; Yeo, B. S.; Louie, M. W.; Miller, D. J.; Sanchez Casalongue, H.; Mbuga, F.; Weng, T.-C.; Nordlund, D.; Sokaras, D.; Alonso-Mori, R.; Bell, A. T.; Nilsson, A. On the Chemical State of Co Oxide Electrocatalysts during Alkaline Water Splitting. Phys. Chem. Chem. Phys. 2013, 15, 17460-17467. 
(22) Han, Y.; Axnanda, S.; Crumlin, E. J.; Chang, R.; Mao, B.; Hussain, Z.; Ross, P. N.; Li, Y.; Liu, Z. Observing the Electrochemical Oxidation of Co Metal at the Solid/Liquid Interface Using Ambient Pressure X-Ray Photoelectron Spectroscopy. J. Phys. Chem. B 2017, 122, 666-671.

(23) Bergmann, A.; Martinez-Moreno, E.; Teschner, D.; Chernev, P.; Gliech, M.; de Araújo, J. F.; Reier, T.; Dau, H.; Strasser, P. Reversible Amorphization and the Catalytically Active State of Crystalline $\mathrm{Co}_{3} \mathrm{O}_{4}$ during Oxygen Evolution. Nat. Commun. 2015, 6, 8625(1-6).

(24) Ross, F. Opportunities and Challenges in Liquid Cell Electron Microscopy. Science. 2015, 350, aaa9886-aaa9889.

(25) Poseidon liquid holder https://www.protochips.com/products/poseidon-select/ (accessed Nov 21, 2018).

(26) de Jonge, N.; Houben, L.; Dunin-Borkowski, R. E.; Ross, F. M. Resolution and Aberration Correction in Liquid Cell Transmission Electron Microscopy. Nat. Rev. Mater. 2019, 4, 61-78.

(27) de Jonge, N.; Browning, N. D.; Evans, J. E.; Chee, S. W.; Ross, F. M. Resolution in Liquid Cell Experiments. In Liquid Cell Electron Microscopy; Cambridge University Press: Cambridge, 2016; pp 164-188.

(28) Reikowski, F.; Maroun, F.; Pacheco, I.; Wiegmann, T.; Allongue, P.; Stettner, J.; Magnussen, O. M. Operando Surface X-Ray Diffraction Studies of Structurally Defined $\mathrm{Co}_{3} \mathrm{O}_{4}$ and $\mathrm{CoOOH}$ Thin Films during Oxygen Evolution. ACS Catal. 2019, 9, 38113821.

(29) Chen, Z.; Kronawitter, C. X.; Koel, B. E. Facet-Dependent Activity and Stability of $\mathrm{Co}_{3} \mathrm{O}_{4}$ Nanocrystals towards the Oxygen Evolution Reaction. Phys. Chem. Chem. Phys. 2015, 17, 29387-29393. 
(30) Potvin, E.; Brossard, L. Oxygen Evolution on Electrochemically Generated Cobalt Spinel Coating. J. Appl. Electrochem. 1955, 25, 462-471.

(31) Kanan, M. W.; Yano, J.; Surendranath, Y.; Dinca, M.; Yachandra, V. K.; Nocera, D. G. Structure and Valency of a Cobalt-Phosphate Water Oxidation Catalyst Determined by In Situ X-Ray Spectroscopy. J. Am. Chem. Soc. 2010, 132, 13692-13701.

(32) Surendranath, Y.; Dincă, M.; Stich, T. A.; Britt, R. D.; Stoian, S. A.; McAlpin, J. G.; Nocera, D. G.; Casey, W. H. EPR Evidence for Co(IV) Species Produced During Water Oxidation at Neutral pH. J. Am. Chem. Soc. 2010, 132, 6882-6883.

(33) Wang, Z. L.; Yin, J. S.; Jiang, Y. D. EELS Analysis of Cation Valence States and Oxygen Vacancies in Magnetic Oxides. Micron 2000, 31, 571-580.

(34) Chen, Z.; Cai, L.; Yang, X.; Kronawitter, C.; Guo, L.; Shen, S.; Koel, B. E. Reversible Structural Evolution of NiCoOxH y during the Oxygen Evolution Reaction and Identification of the Catalytically Active Phase. ACS Catal. 2018, 8, 1238-1247.

(35) Ewels, P.; Sikora, T.; Serin, V.; Ewels, C. P.; Lajaunie, L. A Complete Overhaul of the Electron Energy-Loss Spectroscopy and X-Ray Absorption Spectroscopy Database: Eelsdb.Eu. Microsc. Microanal. 2016, 22, 717-724.

(36) Gupta, S.; Yadav, A.; Bhartiya, S.; Singh, M. K.; Miotello, A.; Sarkar, A.; Patel, N. Co Oxide Nanostructures for Electrocatalytic Water-Oxidation: Effects of Dimensionality and Related Properties. Nanoscale 2018, 10, 8806-8819.

(37) Kanan, M. W.; Surendranath, Y.; Nocera, D. G. Cobalt-Phosphate Oxygen-Evolving Compound. Chem. Soc. Rev. 2009, 38, 109-114.

(38) Lutterman, D. A.; Surendranath, Y.; Nocera, D. G. A Self-Healing Oxygen-Evolving Catalyst. J. Am. Chem. Soc. 2009, 131, 3838-3839.

(39) Costentin, C.; Nocera, D. G. Self-Healing Catalysis in Water. Proc. Natl. Acad. Sci. 2017, 114, 13380-13384. 
(40) Surendranath, Y.; Kanan, M. W.; Nocera, D. G. Mechanistic Studies of the Oxygen Evolution Reaction by a Cobalt-Phosphate Catalyst at Neutral pH. J. Am. Chem. Soc. 2010, 132, 16501-16509.

(41) Jolivet, J.-P.; Henry, M.; Livage, J. Metal Oxide Chemistry and Synthesis : From Solution to Solid State; Wiley: Michigan, 2000.

(42) Pourbaix, M. J. N.; Zoubov, N. de. Atlas d'Equilibres Electrochimiques; GauthierVillars: Paris, 1963.

(43) Wang, H.; Hung, S.; Chen, H.; Chan, T.; Chen, H. M.; Liu, B. In Operando Identification of Geometrical-Site-Dependent Water Oxidation Activity of Spinel $\mathrm{Co}_{3} \mathrm{O}_{4}$. J. Am. Chem. Soc. 2016, 138, 36-39.

(44) Abidat, I.; Cazayus, E.; Loupias, L.; Morais, C.; Comminges, C.; Napporn, T. W.; Portehault, D.; Durupthy, O.; Mamede, A.-S.; Chanéac, C.; Lamonier, J.F.; Habrioux, A.; Kokoh, K. B. $\mathrm{Co}_{3} \mathrm{O}_{4} / \mathrm{RGO}$ Catalysts for Oxygen Electrocatalysis: On the Role of the Oxide/Carbon Interaction. J. Electrochem. Soc. 2019, 166, H94-H102.

(45) Suntivich, J.; Gasteiger, H. A.; Yabuuchi, N.; Shao-Horn, Y. Electrocatalytic Measurement Methodology of Oxide Catalysts Using a Thin-Film Rotating Disk Electrode. J. Electrochem. Soc. 2010, 157, B1263-B1268.

(46) Woehl, T. J.; Evans, J. E.; Arslan, I.; Ristenpart, W. D.; Browning, N. D. Direct In Situ Determination of the Mechanisms Controlling Nanoparticle Nucleation and Growth. ACS Nano 2012, 6, 8599-8610. 